\title{
Gastric impaction and secondary oesophageal obstruction in a pony - the additional value of total body CT in cases of chronic colic
}

\author{
Nienke W. Kuijpers' ${ }^{7}$ Marianne M. Sloet van Oldruitenborgh-Oosterbaan ${ }^{1,2}$ and Stefanie Veraa ${ }^{7}$ \\ ' Department of Clinical Sciences, Discipline of Diagnostic Imaging, Faculty of Veterinary Medicine, Utrecht University, Utrecht \\ ${ }^{2}$ Department of Clinical Sciences, Discipline of Equine Internal Medicine, Faculty of Veterinary Medicine, Utrecht University, Utrecht
}

\begin{abstract}
Summary: A 21 -month old Miniature-Appaloosa stallion was presented to the University Equine Clinic with severe colic, unsuccessful nasogastric intubation and compulsive walking behaviour. A total body computed tomography and a magnetic resonance examination of the head was performed as the horse was too small and in such an agitated status that another diagnostic approach was impossible without general anaesthesia. A large amount of coarse granular mixed soft tissue attenuation material was present in the stomach and caudal part of the oesophagus, with the rest of the abdomen and dental structures found to be within normal limits. Based on the computed tomographic findings the imaging diagnosis was gastric overload and secondary incomplete oesophageal emptying. A primary gastric impaction was suspected and confirmed with gross pathology. The MRI showed no abnormalities; hence no explanation for the agitated behaviour was found other than severe abdominal discomfort caused by the gastric impaction. Inconclusive basic diagnostic work-up of abdominal pathology, including clinical examination and ultrasound, prompts further evaluation. Computed tomographic imaging should be considered a non-invasive and reliable diagnostic modality in the advanced diagnostic work-up in miniature breeds or foals with severe and undefined colic and, such as seen with gastric impaction.
\end{abstract}

Keywords: colic, imaging, horse, stomach, oesophagus

Citation: Kuijpers N. W., Sloet van Oldruitenborgh-Oosterbaan M. M., Veraa S. (2020) Gastric impaction and secondary oesophageal obstruction in a pony - the additional value of total body CT in cases of chronic colic. Pferdeheilkunde 36, 306-31 0; DOI 10.21836/PEM20200403

Correspondence: Dr. Nienke Kuijpers, Division of Diagnostic Imaging, Faculty of Veterinary Medicine, Utrecht University, Yalelaan 108,3584 CM, Utrecht, The Netherlands; n.w.kuijpers@uu.nl

Received: March 11, 2020 | Accepted: March 25, 2020

\section{Introduction}

Equine gastric impaction has been defined as a persistent (after 18-24 hours of fasting) abnormal accumulation of dehydrated, non-expansile, poorly fermentable ingesta in the stomach, eventually resulting in severe gastric dilatation (Owen et al. 1987, Freeman 2011). Gastric dilation has been reported to coincide with impaction (one can induce the other and vice versa) and have been classified as a primary or secondary disorder (Owen et al. 1987).

Causes of primary gastric dilatation and impaction in larger adult horses can be classified further into extrinsic and intrinsic causes (Owen et al. 1987). Reported extrinsic causes include abnormal feeding behaviour (poor mastication/dental disease, irregular or greedy feeding), inappropriate food (old, dry and non-nutritious grasses, persimmon seeds, beet pulp) or inadequate water intake (Owen et al. 1987). Intrinsic causes include defective gastric secretion, gastric atony and pyloric stenosis (Owen et al. 1987).

Secondary gastric dilatation is most commonly found with intestinal obstructions. Gas, liquid and some solid material is usually present in the stomach due to intestinal reflux (Free- man 2011). All diseases causing delaying gastrointestinal transit could be considered as causative factors for secondary gastric dilatation, including obstructive ileus, paralytic ileus, grass sickness, enteritis, ragwort poisoning or pharmacologically induced ileus (Owen et al. 1987, Smith et al. 2015).

Symptoms of gastric impaction together with dilatation are reported to be chronic, consisting mostly of inappetence and recurrent colic, although acute severe colic may also be seen (Doxey et al. 1987, Vainio et al. 2011 ). This is in accordance with the presumed pathogenesis of slowly, sub-clinical ingesta accumulation, impaction and progressive enlargement along the greater curvature with more liquid content passing along the lesser curvature to the duodenum (Freeman 2011, Huskamp et al. 2000, Scheidemann and Huthmann 2011)

Diagnosing gastric impaction can be challenging due to the aspecific clinical signs and difficulties in evaluating the type and amount of content with ultrasound (le Jeune et al. 2014). Although the ultrasonographic parameters of stomach size in ponies have been reported, it remains difficult to evaluate the clinically critical extension and dilatation in the individual horse (le Jeune et al. 2014, Epstein et al. 2008). 
This case report describes a severely agitated Miniature Appaloosa stallion with primary gastric impaction diagnosed non-invasively with computed tomography (CT) and confirmed by post-mortem examination, after excluding central nervous pathology with magnetic resonance imaging (MRI). CT features and the additional value of this imaging modality in cases of colic of unknown origin are discussed.

\section{Case history}

A 21 -month-old Miniature Appaloosa stallion was presented to the University Equine Clinic with a history of recurrent, intermittent symptoms of mild colic for 3.5 months. Treatment with analgesics and nasogastric administration of liquid paraffin by the primary veterinarian provided temporary relief of acute symptoms. However, the colic signs had returned the last few hours with rapidly increasing intensity, and failure of nasogastric intubation due to an obstruction at the level of the caudal oesophagus.

\section{Clinical presentation}

On initial presentation the pony, weighing 80 kilograms, showed inappetence and obsessive walking. It was not possible without excessive force to stop the pony to take respiratory rate, heart rate and body temperature. Mucous membranes were pink and moist and there were no signs of ptyalism or nasal discharge. A jugular blood sample was submitted for haematology and biochemistry. Abnormalities detected included mild leukopenia (4.5 G/L, ref. 7.0-10.0 G/L) and increased liver enzyme activities (gamma-GT $41 \mathrm{IU} / \mathrm{L}$, ref. $<34 \mathrm{IU} / \mathrm{L}$ and ASAT $803 \mathrm{IU} / \mathrm{L}$, ref. 224-492 IU/L).

\section{Diagnostic Imaging}

The pony was severely agitated, that persisted after sedation (detomidine $10 \mu \mathrm{g} / \mathrm{kg}$ i.m. and butorphanol $20 \mu \mathrm{g} / \mathrm{kg}$ i.m.). Hence, for further diagnostic work-up general anaesthesia was induced (diazepam $0.06 \mathrm{mg} / \mathrm{kg}$ i.v., ketamine $2.2 \mathrm{mg} / \mathrm{kg}$ i.v.) and endotracheal intubation was performed. The pony was placed in dorsal recumbency and maintained under general anaesthesia using a triple drip (guaifenesine $100 \mathrm{mg} / \mathrm{kg} / \mathrm{h}$, ketamine $2 \mathrm{mg} / \mathrm{kg} / \mathrm{h}$, detomidine $20 \mu \mathrm{g} / \mathrm{kg} / \mathrm{h}$ ). Considering the possible central neurological signs (excited behaviour and compulsive walking) MRI of the head was performed (Philips Ingenia, 1.5 Tesla') and included transverse T2-TSE, T1-TSE (before and after i.v. contrast administration and subtraction; gadoterate meglumine $0.2 \mathrm{ml} / \mathrm{kg}$ ) and T2*-FFE. CT examination of the pony from head to pelvis was then performed using a 64-slice sliding gantry CT (Siemens Somatom AS²), 140 $\mathrm{kV}$ and variable (Care-for-Dose) $\mathrm{mAs}$ settings, a 0.5 second tube rotation time, a pitch of 0.9 and matrix of $512 \times 512$. The field-of-view was optimized for the patient size. Retrieved data were reformatted in bone (B50s) and soft tissue (B30f) algorithm with $3 \mathrm{~mm}$ slice thickness and $1.5 \mathrm{~mm}$ increment.

MRI examination did not reveal any changes to the central nervous system or surrounding cranial structures. CT examination of the head, cervical and cranial thoracic region revealed no abnormalities. The most caudal part of the oesophagus was filled over a length of $10 \mathrm{~cm}$ with coarse granular soft tissue attenuation (30 HU) material, without causing significant dilatation (figure $1 \mathrm{a}-\mathrm{c}$ ). The material was continuous with a large amount of similar coarse granular soft tissue attenuation material containing many small gas attenuation $(-500 \mathrm{HU})$ foci completely filling the distended stomach (figure $2 a$ ). The stomach extended from the $10^{\text {th }}$ intercostal space to the $15^{\text {th }}$ rib. The gastric wall was considered intact and within normal limits, and the surrounding mesenteric fat homogeneous in attenvation without evidence of streaking or fluid attenuation. The duodenum contained some gas and fluid but was otherwise empty. There was a minimal amount of granular material of soft tissue attenuation (40-60 HU) and some fluid with a horizontal fluid level present in the colon. A small amount of more pasty material was seen in the caecum. Very minimal amounts of highly attenuation $(650 \mathrm{HU})$ material were suspended in the dorsal parts of the colon, consistent with sand. Based on the CT findings the working diagnosis was gastric impaction and possible secondary partial oesophageal obstruction or reflux.

\section{Treatment}

The pony was transported to the recovery room after MRI and CT examinations and endoscopy of the oesophagus was performed after extubation. Presence of coarse feeding material in the caudal oesophagus was revealed, prohibiting further advancement of the endoscope. General anaesthesia was induced again (diazepam $0.06 \mathrm{mg} / \mathrm{kg}$ i.v., ketamine $2.2 \mathrm{mg}$ / $\mathrm{kg}$ i.v.) with endotracheal intubation, and maintained with inhaled isoflurane and a detomidine continuous rate infusion $(10 \mu \mathrm{g} / \mathrm{kg} / \mathrm{h})$.

The pony was brought in left lateral recumbency and lavage of the oesophagus was initiated through a narrow nasogastric tube after providing oesophageal smooth muscle relaxation (butylscopalamine $0.3 \mathrm{mg} / \mathrm{kg}$ i.v.). Repeat endoscopic examination showed that lavage did not succeed in resolving the oesophageal obstruction. Due to further physical deterioration and a poor prognosis for resolving the diagnosed condition, the owner agreed with euthanasia.

\section{Pathological findings}

During gross post-mortem examination, coarse ingesta were present in the caudal part of the oesophagus, not causing significant dilatation or damage of internal wall structures (figure 1d). The stomach was distended, intact, and completely filled with coarse roughage, without visible macroscopic lesions of the stomach wall (figure 2b). The liver appeared macroscopically large and pale. Microscopically, a moderate number of hepatocytes appeared to contain several well-defined fat vacuoles and a mild amount of hepatic portal bridging fibrosis was noted, consistent with the elevated liver enzymes and hepatic lipidosis.

\section{Discussion}

This case report illustrates the added value of CT examination of the equine abdomen. It describes the CT imaging findings of 
primary gastric impaction with secondary oesophageal incomplete emptying in a miniature horse, which have been sparsely described in literature. Differentiation between primary versus secondary causes of gastric dilatation, either in combination with or without impaction and the duration of the gastric changes is considered highly valuable for prognostic appraisal and further treatment planning (Vainio et al. 2011, Parker et al. 2011, Bird et al. 2012). However, the work-up leading to a final clinical diagnosis is considered challenging (Freeman 2011).

Clinical diagnosis of gastric impaction can be confirmed by gastroscopy. Although assessment of gastric size with gastroscopy is limited, a full stomach or a concretion of ingesta after a normally adequate fast (Reed 2018), prohibiting visualization of the margo plicatus and possible wall lesions can be found and is characteristic in gastric impaction (Vainio et al. 2011 , Freeman 201 1, Huskamp et al. 2000). Determining the cause and duration of the condition relies on a combination of other diagnostic procedures to rule out pathologic conditions that could induce impaction or dilatation (Freeman 2011). In the currently described case, endoscopic examination repeatedly failed to reach into the stomach. This was caused by a secondary mechanical obstruction of the distal oesophagus with coarse ingested material making endoscopic gastric assessment impossible (figure 1). Oesophageal obstruction is mostly caused by intraluminal obstruction of inappropriate ingesta (Feige et al. 2000), however, gastric impaction with secondary oesophageal stasis or reflux should be considered as a differential diagnosis as is documented in this case.

Rectal examination can reveal caudoventral displacement of the spleen in a case of gastric dilatation, which then can be palpated just cranial to the pelvic brim (Parker et al. 2011). Palpation of the gastric impaction itself has incidentally been
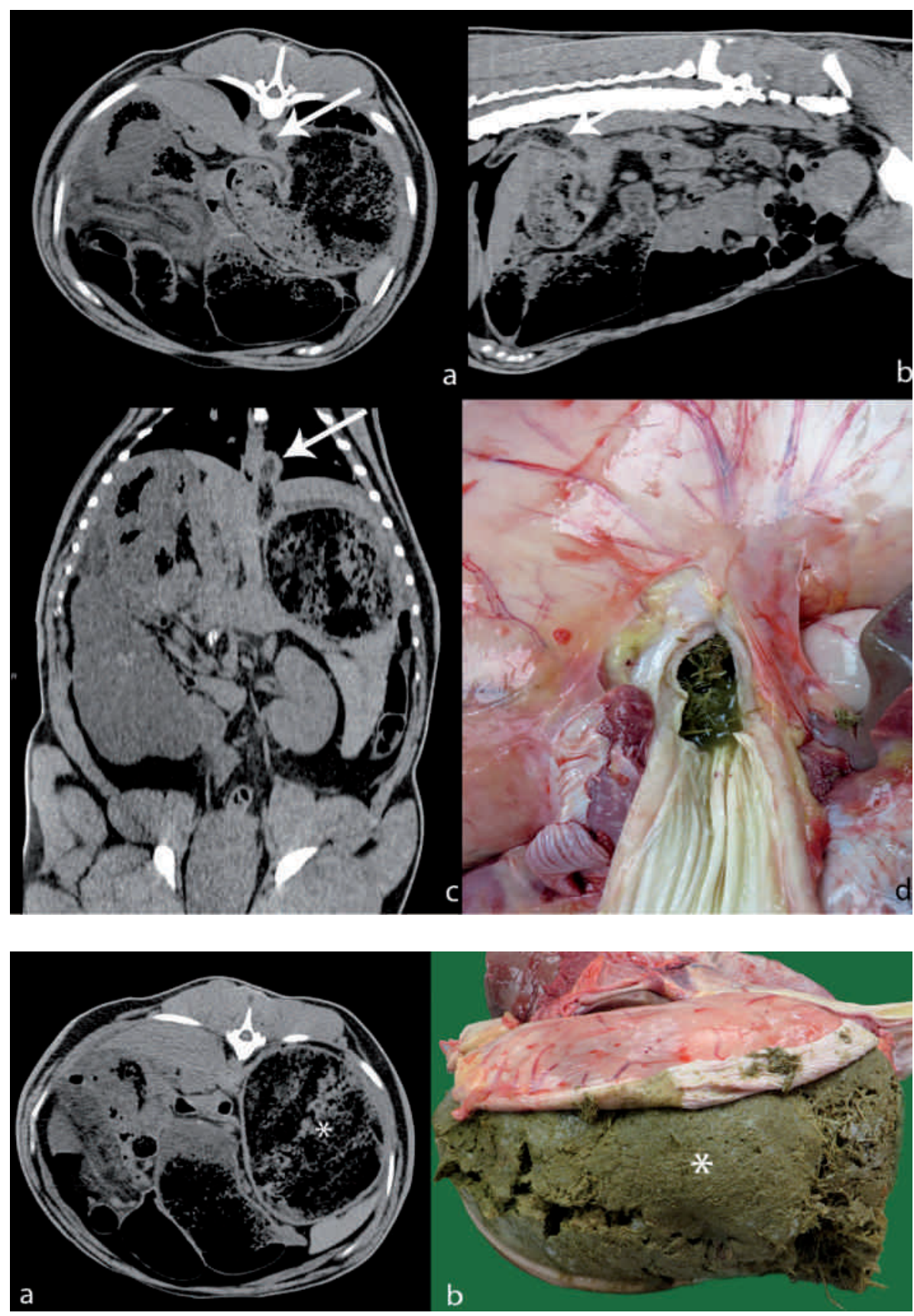

Fig. 1 Clockwise display of a transverse (a), sagittal (b) and dorsal (c) planar soft tissue reconstruction of the abdominal CTimages of the Miniature pony. Abnormal mixed soft tissue attenuation coarse content is visible within the caudal oesophagus (white arrow), indicating secondary oesophageal obstruction or reflux, confirmed during gross pathological examination (d). I Darstellung im Uhrzeigersinn einer transversalen (a), sagittalen (b) und dorsalen (c) planaren Weichteilrekonstruktion der Bauch-CT-Bilder des Miniaturponys. Ein abnormaler, gemischter Weichteilabschwächungs-Grobanteil ist innerhalb der kaudalen Speiseröhre sichtbar (weißer Pfeil), was auf eine sekundäre Speiseröhrenobstruktion oder einen Reflux hinweist, der bei der grobpathologischen Untersuchung bestätigt wurde (d).

Fig. 2 a: Transverse CT image of the cranial abdomen of the Miniature horse showing a distended stomach filled with a large amount of coarse granular soft tissue attenuation material mixed with gas attenuations (white asterisk). b: Gastric impaction (white asterisk) was confirmed during gross pathological examination. | Quer-CT-Aufnahme des Schädelbauches des Miniaturpferdes, die einen aufgeblähten Bauch zeigt, der mit einer großen Menge grobkörnigen Weichteildämpfungsmaterials, gemischt mit Gasdämpfungen, gefüllt ist (weißes Sternchen). b: Die Magenimplantation (weißes Sternchen) wurde bei der groben pathologischen Untersuchung bestätigt. 
reported (Owen et al. 1987). Scheidemann and Huthmann (2011) described that they were able to palpate in adult horses the enlarged stomach as a convex firm structure on the right of the caudally deviated spleen if the stomach was filled with more than $30 \mathrm{~kg}$ content. Rectal examination was not feasible in this miniature breed due to size limitations and agitated behaviour. Transabdominal ultrasonography is considered a safe, readily available and non-invasive diagnostic tool to evaluate gastric size in patients with abdominal discomfort; however gastric wall thickness and luminal contents are only partially visible (le Jeune et al. 2014, Epstein et al. 2008). Caudoventral displacement of the spleen (Huskamp et al. 2000) and increased visibility of the adjacent stomach wall over more than 5 intercostal spaces can be inconsequently seen in cases of gastric dilatation (Kidd et al. 2014, le Jeune et al. 2014, Bird et al. 2012). Although ultrasonographic examination could have also provided diagnostic information, in this case, transabdominal ultrasonographic examination was not performed, due to the excited and uncooperative behaviour of the patient.

General anaesthesia was needed in order to be able to perform further diagnostics. The small size of the patient and the general anaesthesia induced recumbency steered the diagnostic work-up to the rather unconventional next step of advanced imaging, which were readily available in this specialised clinic. Also, nasogastric intubation and gastric lavage clearly weren't feasible. Together with the vague neurologiclike excited symptoms of the patient, this led to the decision to make a further advanced imaging inventory before moving on to more invasive procedures.

CT imaging of the intestinal tract in this case, allowed a multi-planar and detailed evaluation of the position, wall structure and luminal content of the intestines, excluding most causes for secondary gastric impaction or dilatation. Transabdominal ultrasonographic evaluation of the intestinal tract can also identify intestinal obstruction, resulting in secondary gastric dilatation or impaction (Fontaine et al. 1999), though complete evaluation of the intestinal tract is limited by acoustic window, scan depth and intestinal gas related reverberation artefacts (le Jeune et al. 2014). Despite the fact that abdominal CT in larger horses is limited by CT bore size and the risks associated with general anaesthesia (Senior 2013), the major advantage of CT examination is the lack of superimposition of adjacent structures. This facilitates the detailed observation of the closely positioned abdominal organs. In addition, fullbody CT examination allows a total work-up of the patient. CT showed in this case normal head structures, which further excludes dental, sinus or mastication abnormalities as an extrinsic cause for gastric impaction. Since there was no history of abnormal feeding stuff, feeding behaviour or inadequate water intake, a high suspicion of a primary intrinsic gastric disorder, such as gastric atony was raised, which generally carries a grave prognosis (Smith et al. 2015). Unfortunately, further histologic evaluation of the gastric wall was not performed.

\section{Conclusion}

Advanced imaging work-up provided the appropriate tool in this case, as a basic work-up was not possible or inconclusive. $\mathrm{CT}$ imaging findings consistent with primary gastric impaction with secondary oesophageal obstruction were described and confirmed by post-mortem examination. In the current case report, CT examination has offered differentiation of possible underlying causes. CT examination could thus be considered a valuable added diagnostic approach in the clinical workup of miniature breed horses or foals with poorly understood abdominal discomfort.

\section{Acknowledgements}

The authors would like to thank Guy Grinwis DVM, PhD, Spec. KNMvD Veterinary Pathology of the Department of Pathobiology for performing, interpreting and reporting the post-mortem examination.

\section{Manufacturer's addresses}

1 Phillips Medical Imaging, Eindhoven, The Netherlands

2 Siemens Health Care Diagnostics B.V., Den Haag, The Netherlands

\section{References}

Bird A. R., Knowles E. J., Sherlock C. E., Pearson G. R., Mair T. S. (2012) The clinical and pathological features of gastric impaction in twelve horses. Equine Vet. J. 44, 105-110; DOI 10.1111/ j.2042-3306.2012.00774

Blikslager A. T. (2005) Treatment of gastrointestinal obstruction-stomach impaction, ileal impaction, and cecal impaction. AAEP focus meeting, Quebec, Canada.

Doxey D., Milne E., Rowlan A., Pogson D. (1987) Equine gastric primary impaction. Vet. Rec. 121, 263-264; DOI 10.1136/ vr. 121.11 .263

Epstein K., Short D., Parent E., Reef V., Southwood L. (2008) Gastrointestinal ultrasonography in normal adult ponies. Vet. Radiol. Ultrasound 49, 282-286; DOI 10.1111/i.1740-8261.2008.00367.x

Feige K., Schwarzwald C., Fürst A., Kazer-Hotz B. (2000) Oesophageal obstruction in horses: a retrospective study of 34 cases. Can. Vet. J. 41, 207-210

Fontaine G. L., Hanson R. R., Rodgerson D. H., Steiger R. (1999) Ultrasound evaluation of equine gastrointestinal disorders. Comp. Cont. Educ. Pract. Vet.21, 253-262

Freeman D. E. (2011) Gastric impaction. Equine Vet. Educ. 23, 174 176; DOI10.1111/j.2042-3292.2010.00206.x

Huskamp B., Scheidemann W., Schusser G. F. (2000) Some rare diseases of the stomach and duodenum in the adult horse: biphasic rupture of the stomach, chronic gastric dilatation, dilatation of the duodenum, duodenal torsion. Prakt. Tierartzt 82, 729-736

Epstein K., Short D., Parente E., Reef V., Southwood L. (2012) Gastrointestinal ultrasonography in normal adult ponies. Vet. Radiol. Ultrasound 49, 282-286; DOI 10.11 11/i.1740-8261.2008.00367.x

Jeune S. le, Whitcomb M. B. (2014) Ultrasound of the Equine Acute Abdomen. Vet. Clin. North Am. Equine Pract. 30, 353-381; DOI 10.1016/j.cveq.2014.04.011

Kidd J. A., Lu K. G., Frazer M. L. (2014) Atlas of equine ultrasonography. 1st ed., Ed Wiley Hoboken. pp 427-428 ISBN 9781118798126

Owen R., Jagger D., Jagger F. (1987) Two cases of equine primary gastric impaction. Vet. Rec. 121, 102-105; DOI10.1136/ vr.121.5.102

Parker R. A., Barr E. D., Dixon P. M. (2011) Treatment of equine gastric impaction by gastrotomy. Equine Vet. Educ. 23, 169-173; DOI 10.1111/i.2042-3292.2010.00165.x 
Reed S., Warwick B., Sellon D. (2018) Diseases of the stomach. In: Equine Internal Medicine. $4^{\text {th }}$ ed., Saunders., 808 ISBN 9780323445528

Scheideman W., Huthmann S. (2011) A contribution to disease of the equine stomach: chronic gastric impaction and dilatation. J. Vet. Intern. Med. 25, 624

Smith B. P., Ainsworth D. S. (2015) Diseases of the alimentary tract. In: Large Animal Internal Medicine. 5th ed., Ed: B. Smith, Elsevier, Mosby, St. Louis, Missouri. p 373 ISBN 9780323088398
Senior J. M. (2013) Morbidity, mortality, and risk of general anesthesia in horses. Vet. Clin. Equine 29, 1-18; DOI10.1016/i. creq.2012.11.007

Vainio K., Sykes B. W., Blikslager A. T. (2011) Primary gastric impaction in horses: A retrospective study of 20 cases (20052008). Equine Vet. Educ. 23, 186-190; DOI 10.1111/i.20423292.2010.00153.x 